\title{
Photovoltaic System to Save Energy in Jordan: A Case Study on a Semi-detached House
}

\author{
Rizeq N. S. Hammad \\ Architectural Department, Jordan University Amman, Jordan
}

\begin{abstract}
A photovoltaic system is installed, since 5 years in a medium size house in Amman city, Jordan to support the electrical system of the house. The system consents from 14 boards, converter, and two-way electrical meter. Each board is producing 240 watts/hour as a maximum, and the total watts produces from the system is $3.5 \mathrm{~kW} / \mathrm{h}$, this is in an ideal situation, when the sun is perpendicular to the system. The total $\mathrm{kW}$ produced from the system in 4 years is approximately 24,000 , with an average of 6,000 $\mathrm{kW} /$ annual; and $500 \mathrm{kw} /$ month, which is equal to $50 \%$ of the total house consumption. With respect to cost, it reduces the monthly bills to $1 / 6$ of the monthly cost in summer, and $1 / 3$ of the monthly cost in winter. The total cost of the system at installation time, 4 years ago, is $\$ 6,000$, and accordingly the system rewards, its cost in 5 years. The cost of the system now is one-third of the previous cost; and the government is encouraging householder to support their homes by photovoltaic system by giving them one-third of the cost as cash money. Jordanian banks are now accepting monthly payment of the system without additional cost. This system does not only reduce the electrical load from the main electrical board, but also reduces the government oil bill, as Jordan is a poor country with respect to oil and other resources, but is also helping to reduce the pollution caused by burning conventional oil.
\end{abstract}

Key words: Photovoltaic, electrical board, renewable energy.

\section{Introduction}

Jordan is one of the deprived countries with respect to conventional energy resources, while it is an ideal site for renewable energy resources; such as, sun and wind; more than 300 sunny days/year is counted and the wind is also available on daily basis in many locations. In order to protect and secure people's health and environment, effective sustainable solid waste management occupies great importance. Rapid urbanization, insufficient financial resources, and growing population of Jordan present a crucial and alarming challenge, opposing the local government. Energy remains a topmost challenge in Jordan for the growth and development. The energy is required to be created and produced in an effective and sustainable way, possibly from the renewable energy. Jordan has acknowledged that the development of affordable

Part of this research is presented in ICEWES, 2018 Ras Al-Khaimeh, UAE.

Corresponding author: Rizeq Hammad, Prof. Dr., research field: building engineering. energy solutions is crucial to support industries. Solid waste can be utilized to generate electricity as well in some centralized plants; and this approach has also been identified effective to enhance the recycling rates in the country.

This renewable energy was started on a small scale in Jordan 20 years ago to support the water pumps, lighting in far locations; however, as a large-scale project it is started a few years back [1]. It happens, when the government allows connecting the small systems to the main electrical board; therefore, it reduces the storage cost, which is approximately $40 \%$ of the total cost [2].

Photovoltaic (PV) systems are now spreading to cover the private house, schools, universities, hospitals, and mosques. Many private individuals are also read to sell the electricity to the main electrical board [3]. The cost of such system is reducing, and the efficiency is increasing. The government is supporting household by one third of the total cost, and the Jordanian banks are supporting them by monthly payments of the 
system without additional cost or mortgages.

The study has focused on a photovoltaic system, installed since 4 years in a private house, and giving the monthly, annual, and 4-year watts. It has also discussed total reduction in the electric bills, and the total money saving during this period. There is a need for renewable energy training and education, which has been identified globally at all levels. A large number of nations across the globe have started academic programs during the last decades on renewable energy technologies and other relevant factors. Therefore, the study has presented the importance of renewable energy, particularly the photovoltaic energy in Jordan and other poor nations. The review contributed to analyzing and evaluating the best savings for system considering the consumption of energy as well and suggested that more PV boards must be utilized.

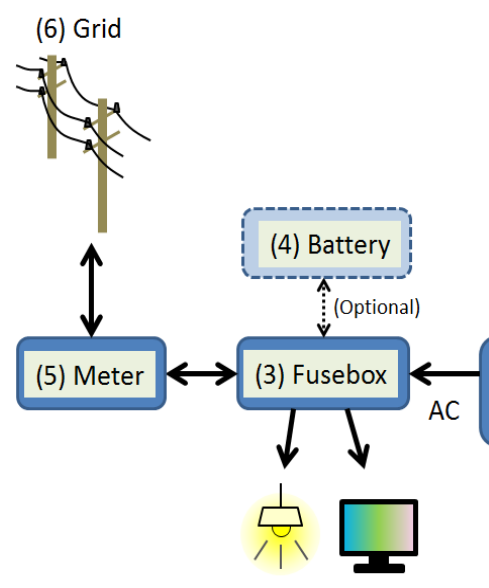

Fig. 1 The system parts.

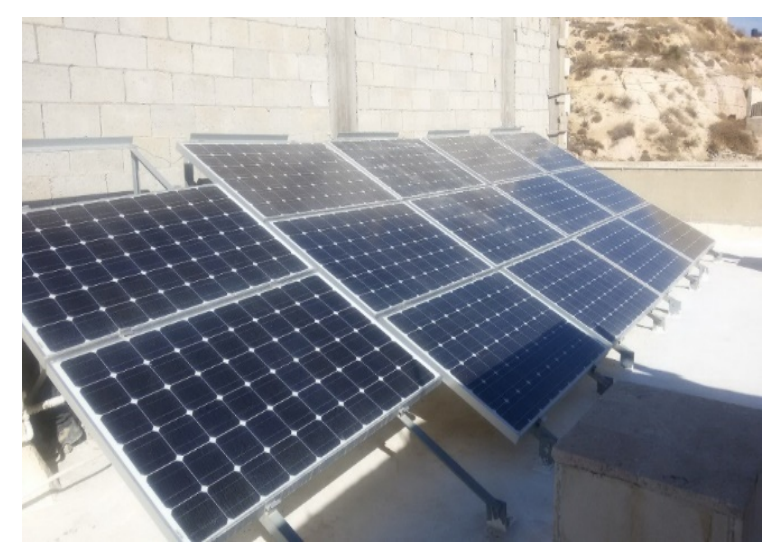

Fig. 2 The 14 photovoltaic boards.

\section{The System Parts}

The system is consisted of 14 photovoltaic boards, connected to the special converter and connected to two ways electrical meter, which is connected to the main electrical board to support the house during the night. When the system is producing more electricity than the house consumption, this amount is transferred to the main board to be reduced from the monthly bill. Fig. 1 shows the system parts and connection; whereas, the real parts of the system are shown in Figs. 2-4.

A number of photovoltaic arrays, transformers, processors, and converters are included in the power conversion system. The processors are structured and developed to control a number of inverters and control the conversion system of power to supply maximum efficiency with the assistance of a number of inverters, transformers, and PV arrays. PV arrays are specifically

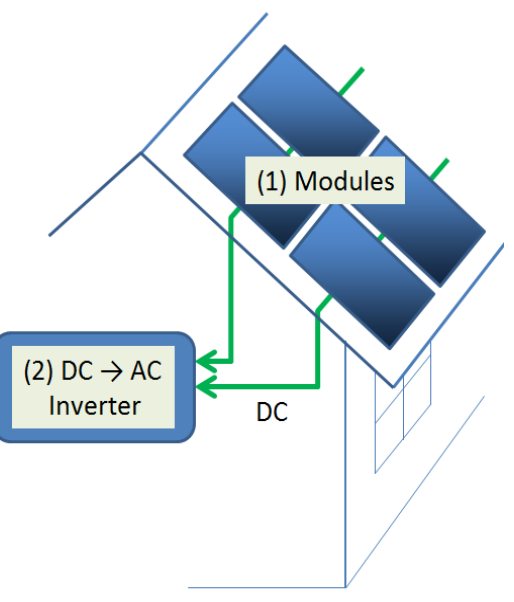

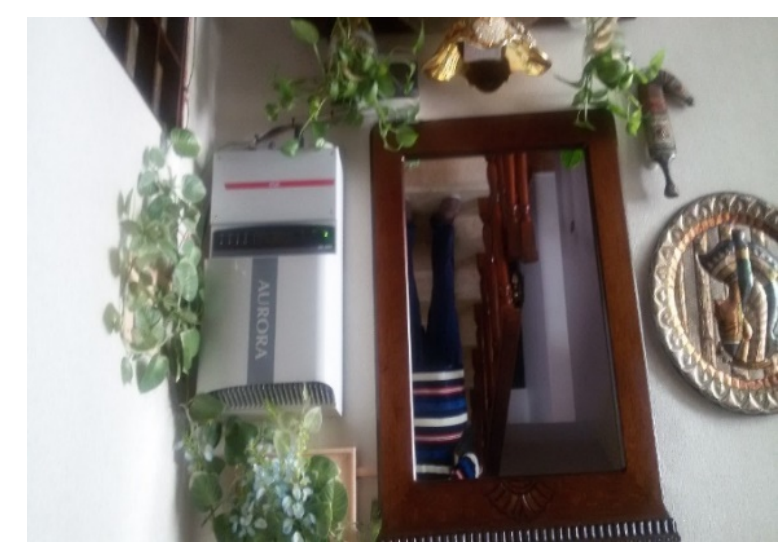

Fig. 3 The converter. 


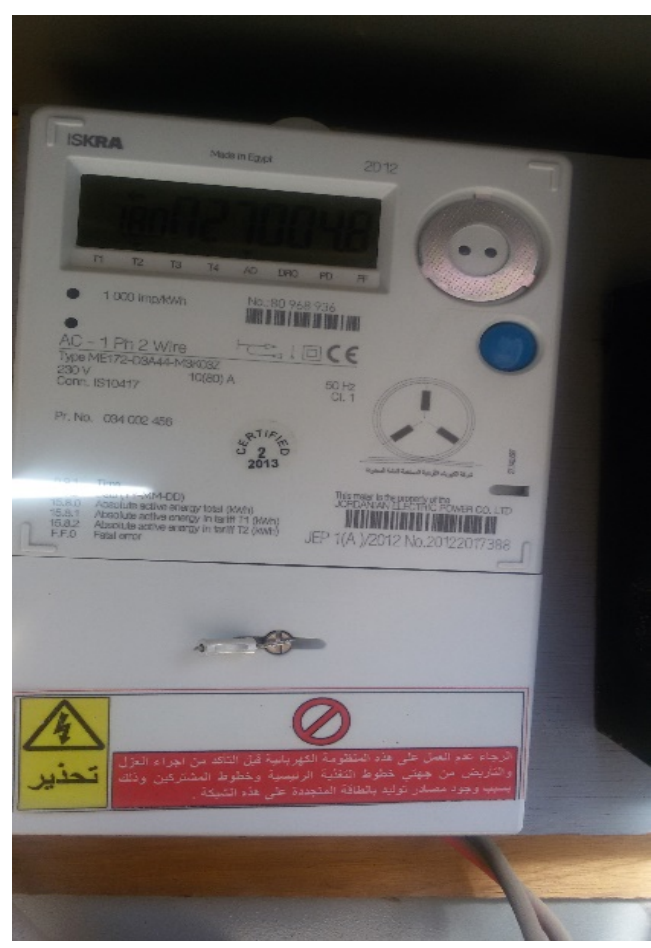

Fig. 4 The two ways electrical meter.

arranged in parallel or series arrangement of PV modules plurality. The traditional type of practice is to ensure that the voltage of generated direct current of PV modules string does not surpass the insulation ratings of the $\mathrm{PV}$ modules.

As shown in the figures, the system is very simple; an ordinary person with limited knowledge can assemble different parts, and the board can be a part of the building elevations or roof. The converter can be fixed anywhere in the house, with a size of $0.5 \times 0.3 \mathrm{~m}$ with a $0.2 \mathrm{~m}$ depth as a decorative element.

\section{System Efficiency}

The average monthly production of the system during the 4 years is shown in Fig. 5, which ranges from $490 \mathrm{~kW}$ to $550 \mathrm{~kW}$, and the minimum average monthly production is recorded at 2015 . The average production is approximately $6,000 \mathrm{~kW} /$ annual, or 17 $\mathrm{kW} /$ day. The average production of each panel is equal to $36 \mathrm{~kW} /$ month or $1.2 \mathrm{~kW} /$ day, and 0.15 $\mathrm{kW} /$ hour, assuming an 8 hours sun duration/day. The maximum $\mathrm{kW} / \mathrm{h}$ is recorded as 3.3 during spring and autumn, while it was maximum $(2.5 \mathrm{~kW} / \mathrm{h})$ during hot summer days. It is an indication that the system is negatively affected by high temperatures.

Fig. 6 is representing the average monthly production of the system during 4 years. This production is varied from $300 \mathrm{~kW} /$ month during winter and $650 \mathrm{~kW} /$ month during summer. The result of sun duration is 10 hours during winter and 14 hours during summer.

The cost of the electricity in Amman city is shown in Fig. 7, where the average cost JD $0.13 / \mathrm{kW}$, for a home of consumption is $1,000 \mathrm{~kW} /$ month. The cost of the electricity is dependent on the monthly consumption. The first $160 \mathrm{~kW} /$ month is JD 0.033 , and JD 0.188 for the slice between $850-1,000 \mathrm{~kW}$. This cost is increasing according to the oil price $(\$=$ JD 0.71).

If the total consumption of the house is $600 \mathrm{~kW}$, then the price is JD 50; while if the total consumption is $1,000 \mathrm{~kW}$; the cost is JD 120. Similarly, if the consumption is equal to $2,000 \mathrm{~kW} /$ month, the cost of the electrical bill is JD 380. Fig. 8 is showing net

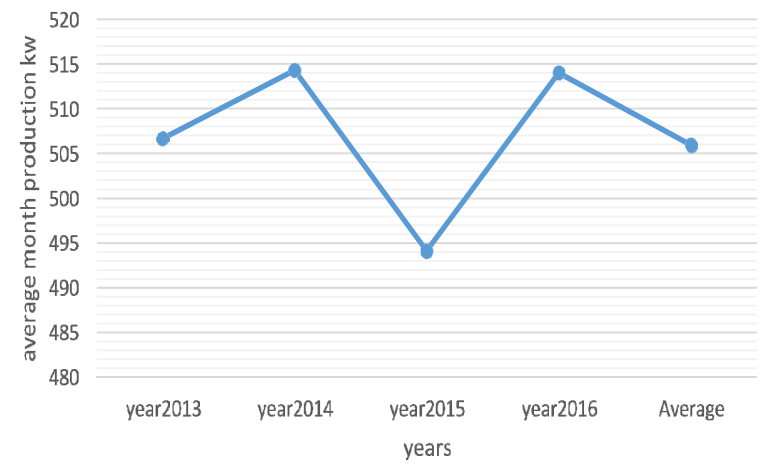

Fig. 5 The average monthly output of the system IN kWatts/year.

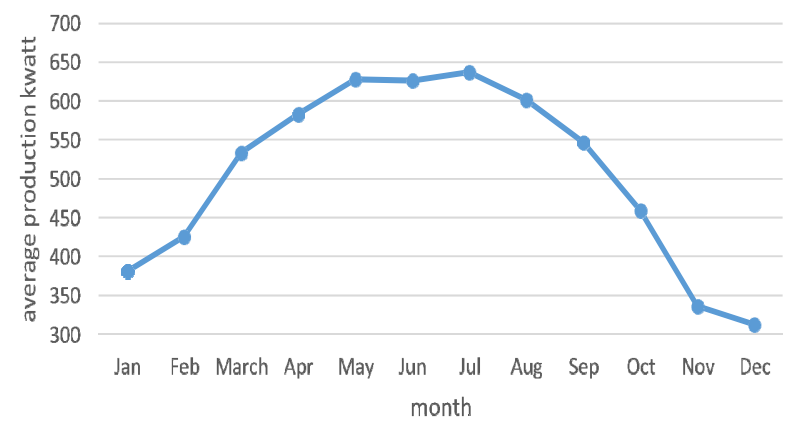

Fig. 6 Average monthly production of the system in kWatts/month. 


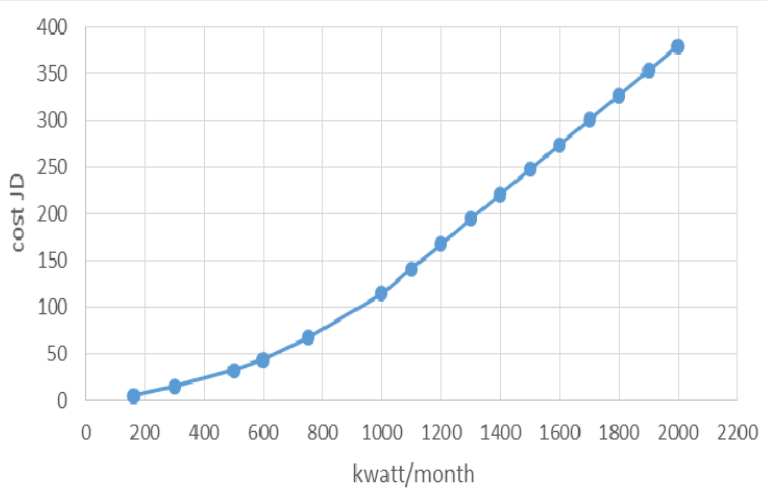

Fig. 7 The total cost of the electricity bill in Amman city in 2016.

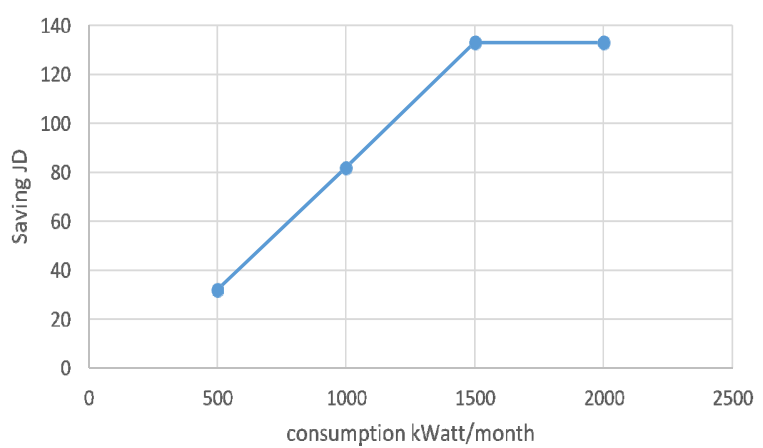

Fig. 8 The net money saving with respect to monthly consumption.

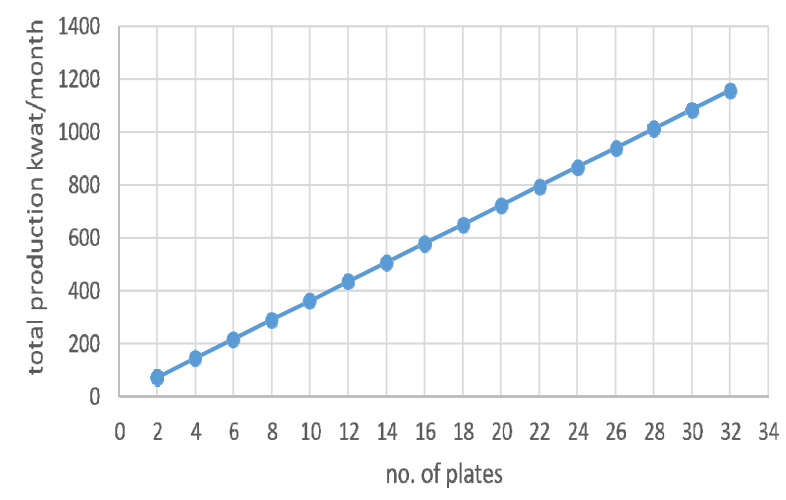

Fig. 9 The total $\mathrm{kW} /$ month production as function of plate number.

saving as a function of the monthly electrical consumption for the above system. It is important to mention that the electrical board is allowing the installation of a $3 \mathrm{kw} / \mathrm{h}$ only system for small houses. If the consumption is $500 \mathrm{~kW} /$ month, the saving is only JD 38, and JD 80 if the consumption is 1,000 $\mathrm{kW} /$ month. The best saving (JD 130) occurs, when the monthly consumption is $1,500 \mathrm{~kW}$.
The total cost of the system was JD 5000 since 7 years ago, which means that the system will cover the cost of installation within $38,62,131$ months, if the monthly home consumption is $1,500 \mathrm{~kW}, 1,000 \mathrm{~kW}$, and $500 \mathrm{~kW}$, respectively. For home consumption above $1,500 \mathrm{~kW}$, the saving will be constant, and the system should be increased to produce $6 \mathrm{~kW} / \mathrm{month}$ and above.

The total $\mathrm{kW} /$ month production of the system as a function of a number of photovoltaic plates is shown in Fig. 9. If the system is producing $6 \mathrm{~kW} / \mathrm{month}$, the average $\mathrm{kW} /$ month will increase to 1,200 , which will be suitable for a home of more than $2,000 \mathrm{~kW} /$ month consumption. It is also possible to choose the number of plates for a certain monthly consumption. In past years, an increasing focus has been placed towards the solar energy usage and its effectiveness [4]. The main benefit of the photovoltaic systems used for joining solar energy is the insufficient low cost of maintenance, greenhouse gas emission and few limitations concerning the absence of mechanical noise coming from moving parts and site of installation. Although, photovoltaic systems suffer from comparatively low conversion effectiveness [5]. Therefore, increasing power tracking of the solar system is important and proved to be significant in a PV system. The changes in the maximum power point and the nonlinear behavior of PV systems complicate the maximum power point tracking with solar temperature and irradiance level. Reisi et al. [6] proposed several maximum power point tracking methods based on different characteristics that included online offline and hybrid techniques. It was reported that future investigations can take advantage from these to generate PV power. The study further discussed the PV system and its dynamic response to variations in irradiance and temperature, implementation and attainable effectiveness.

The constant rise in the level of greenhouse gas emissions and the increasing toll of fuel prices are the major forces that drive the efforts to use different 
renewable energy sources [7]. Solar energy occupies an appropriate place for different applications among renewable sources of energy, essentially because of the probability of direct conversion into electrical energy with the use of PV systems. However, the use of PV system in place of any other source of energy needs a potential amount of investment. The cost of PV systems can be reduced, but the maximum power extraction from solar cell becomes an important concern for the optimal design of the system. At a suitable point of operating a solar cell, maximum power of output depends on the radiation intensity, load impedance, and ambient temperature.

\subsection{High Concentration PV System}

The electric power generation from solar radiation with the assistance of photovoltaic conversion is conquered through technologies by utilizing one material for solar cell. This technique restricts the conversion efficiency to around $25 \%$ [8]. However, the highest efficiencies can be approached by utilizing multi-junction solar cells, but their cost of fabrication still poses a restricting factor. Therefore, the sunlight is gathered by concentrating optics and focused on a relatively small PV receiver. Therefore, it has been identified that this technology constitutes expensive PV cell material through an inexpensive optical instrument. This technique effectively declines the cost per produced $\mathrm{kW}$ [9].

A study by Zhang et al. [10] presented a hybrid approach to improve the economic value and effectiveness of concentrating photovoltaic system. High concentration photovoltaic-thermal system technique depends on the photovoltaic electric power generation in contrast with the use of the wasted thermal energy passed by the coolant. This idea has been evaluated through a new design of a receiver package that consisted of a single-junction GaAs with a directly integrated water-cooled heat sink. It was represented that the cooling needs of the photovoltaic cells can be effectively addressed by concurrently gaining high energetic effectiveness and empowering the use of heat generated.

\section{Technique for Providing Maximum Power Efficiency for PV System}

The cost of solar modules along with its installation is comparatively high; and this is the reason behind extracting the energy from PV array and transformer [6]. During the daylight, temperature and the sunlight conditions of PV modules transform; therefore, a transformer and inverter at their particular highest efficiencies is vital for operating a PV array. The efficiency of the transformer is fixed and the characteristics of the transformer's efficiency are selected to have the highest efficiency that is near to $10 \%$, when the inverter is not placed at its peak efficiency. PV array outputs can be operated by two or more inverters individually. A number of inverters and independent $\mathrm{PV}$ arrays can be selected advantageously based on the output AC power. The system can be optimized based on the availability of the energy storage, particularly for the purpose of energy conversion efficiency. These requirements are approached by the personification of the revealed ideas, which maximize the energy introduced into a load by operating a photovoltaic system at the maximum effectiveness of conversion from the PV array.

According to the one aspect of revealed idea, a method is used for power tracking of the PV system that includes a number of inverters, transformers, and PV arrays [11]. The method contains the control of PV system, including the number of inverters, PV arrays, and transformers to provide maximum efficiency of power conversion. The method may further assist to employ as the number of PV arrays a plurality of PV arrays. The method may further consist of determining the power and energy at the utility grid, which determines the loadings on the number of transformers and inverters and operating the system at the level of optimal stress. 


\section{Conclusion}

Renewable energy is the ultimate green energy, in particular, the photovoltaic energy, for Jordan and other poor countries. This energy is emerging in all around the world, and in Jordan, where many small and large projects are already installed and will stall in the next few years. A home system is installed; since 4 years and monitored to examine the efficiency of such systems. This system is producing a maximum of 3 $\mathrm{kW} / \mathrm{h}$, which is allowable load determined by the electrical board in Jordan. A total $\mathrm{kW}$ produced by the system in the 4 monitored years is 24,000 , with 6,000 $\mathrm{kW} /$ annual and $500 \mathrm{~kW} / \mathrm{month}$. The best saving for a $3 \mathrm{~kW} / \mathrm{h}$ system is $1,500 \mathrm{~kW} /$ month consumption, and if the consumption is increased, then the more photovoltaic board should be used.

\section{Acknowledgement}

The author is very thankful to all the associated personnel in any reference that contributed in/for the purpose of this research. This research holds no conflict of interest and is not funded through any source.

\section{References}

[1] Jaber, J. O., Awad, W., Rahmeh, T. A., Alawin, A. A., Al-Lubani, S., Dalu, S. A., er al. 2017. "Renewable Energy Education in Faculties of Engineering in Jordan: Relationship between Demographics and Level of Knowledge of Senior Students." Renewable and Sustainable Energy Reviews 73: 452-9. Doi: https://doi.org/10.1016/j.rser.2017.01.141.

[2] Hoppmann, J., Volland, J., Schmidt, T. S., and Hoffmann, V. H. 2014. "The Economic Viability of Battery Storage for Residential Solar Photovoltaic Systems-A Review and a Simulation Model." Renewable and Sustainable Energy Reviews 39: 1101-18. Doi: https://doi.org/10.1016/j.rser.2014.07.068.
[3] Pedersen, M. B., Nygaard, I., and Wehrmeyer, W. 2017. "Rural Electrification through Private Models: The Case of Solar-powered Mini-grid Development in Kenya: Exploring the Hybrid Nature of Private Business Models and the Interplay between New Players and Existing Structures in the Kenyan Rural Electrification Regime." Ph.D. thesis, Technical University of Denmark, Denmark.

[4] Ellabban, O., Abu-Rub, H., and Blaabjerg, F. 2014. "Renewable Energy Resources: Current Status, Future Prospects and Their Enabling Technology." Renewable and Sustainable Energy Reviews 39: 748-64. Doi: https://doi.org/10.1016/j.rser.2014.07.113.

[5] Chandrasekar, M., Rajkumar, S., and Valavan, D. 2015. "A Review on the Thermal Regulation Techniques for Non Integrated Flat PV Modules Mounted on Building Top." Energy and Buildings 86: 692-7. Doi: https://doi.org/10.1016/j.enbuild.2014.10.071.

[6] Reisi, A. R., Moradi, M. H., and Jamasb, S. 2013. "Classification and Comparison of Maximum Power Point Tracking Techniques for Photovoltaic System: A Review." Renewable and Sustainable Energy Reviews 19: 433-43. Doi: https://doi.org/10.1016/j.rser.2012.11.052.

[7] Lobell, D. B., Naylor, R. L., and Field, C. B. 2014. Food, Energy, and Climate Connections in a Global Economy. Oxford: Oxford University Press.

[8] Green, M. A., Emery, K., Hishikawa, Y., Warta, W., and Dunlop, E. D. 2015. "Solar Cell Efficiency Tables (Version 45)." Progress in Photovoltaics: Research and Applications 23 (1): 1-9. Doi: 10.1002/pip.2573.

[9] Zimmermann, S., Helmers, H., Tiwari, M., Paredes, S., Michel, B., Wiesenfarth, M., et al. 2015. "A High-efficiency Hybrid High-concentration Photovoltaic System." International Journal of Heat and Mass Transfer 89: 514-21. Doi: https://doi.org/10.1016/j.ijheatmasstransfer.2015.04.068.

[10] Zhang, F., Thanapalan, K., Procter, A., Carr, S., and Maddy, J. 2013. "Adaptive Hybrid Maximum Power Point Tracking Method for a Photovoltaic System." IEEE Transactions on Energy Conversion 28 (2): 353-60.

[11] Bhavaraju V., Peplinski, R. P., and Prasai, A. 2016. Power Conversion System and Method Providing Maximum Efficiency of Power Conversion for a Photovoltaic System, and Photovoltaic System Employing a Photovoltaic Array and an Energy Storage Device. Eaton Corporation. U.S. Patent 9,502,904. 